\title{
A RARE CASE OF LARGE VESICAL CALCULUS AROUND A PROLONGED DOUBLE J STENT: A CASE REPORT
}

\author{
Sunil Kr Ghosh, Dwaipayan Debnath, Mani Ranjan Debbarma, B. C. Medhi, Diptendu Chaudhury
}

1. Assistant Professor. Department of General Surgery, Agartala Government Medical College \& GBP Hospital.

2. Post Graduate Trainee, Department of General Surgery, Agartala Government Medical College \& GBP Hospital.

3. Senior Resident. Department of General Surgery, Agartala Government Medical College \& GBP Hospital.

4. Professor \& HOD. Department of General Surgery, Agartala Government Medical College \& GBP Hospital

5. Post Graduate Trainee, Department of General Surgery, Agartala Government Medical College \& GBP Hospital.

\section{CORRESPONDING AUTHOR:}

Dr Sunil Kr Ghosh,

Kunjaban, Township (behind SBI),

Agartala, Tripura (West),

Pin- 799006.

E-mail: sunilkrghosh752@gmail.com

ABSTRACT: D/J stents constitute an important armamentarium in the hands of an urosurgeon. During short term placement (4-12) weeks, they may cause flank pain and irritative voiding symptoms, referred to as "stent syndrome." Complications occur in patients with long term placement of stents who do not come for follow-up - the forgotten stent. We report a female case with something coming out from external meatus since 2 days with past history of open surgery for right PUJ obstruction with D/J stent insertion 9 years ago. X-ray KUB \& USG abdomen shows a huge vesical calculus around remaining of the $\mathrm{D} / \mathrm{J}$ stent. We operated the case with good outcome. This type of rare presentation of D/J stent motivate us to report this case.

KEY WORDS: Stent complications, DJ stents, Encrusted stents

INTRODUCTION: The double J (D/J) stent provides a convenient means of drainage for the upper urinary tract. However, a forgotten stent is frequently complicated and poses a management and legal dilemma. Despite tremendous advances in stent biomaterials and design, JJ stents are not free of complications and problems. ${ }^{1}$ The presence of the stent provides a framework for deposition of urine constituents. To prevent encrustation, dilution of the urine with high fluid intake and aggressive treatment of any urinary tract infection should be undertaken. ${ }^{2}$ We report a case of a lady presenting to us with an encrusted D/J stent coming out per urethra. After completing all investigations lady was diagnosed to have a huge vesical calculus. We performed supra-pubic cystolithotomy for removing such huge vesical calculus and achieved an excellent outcome.

CASE REPORT: A 45 years lady presented to our department with complains of something coming out per urethra with difficulty on micturition since two days. She had past history of open kidney surgery for right renal stone nine years back. As patient did not produce any documents, the type of surgery, indication and whether any stent used is not clear to us. Her general and systemic examination was almost normal except a long scar in the right loin. On local examination one encrusted tube (stent) was coming out per urethra. On pulling it almost whole of the encrusted tube (stent) comes out. X ray KUB, USG whole abdomen, CT whole 
abdomen IVU shows a large vesical calculus of $8.5 \times 7 \mathrm{~cm}$. After completing all routine investigations, supra pubic cystolithotomy was done under spinal anaesthesia. A huge vesical calculus removed which on proper examination seems to have the remaining part stent impacted on it. From that it is almost clear that this huge calculus was formed on that part of the stent which was in the urinary bladder. The whole post operative period was uneventful and the patient was discharged on $10^{\text {th }}$ post operative day with advice to attend surgical outpatient department for follow up.

DISCUSSION: The double J stent is a double-edged weapon and, though it is regularly used, not always justified. Certain precautions and guidelines should be abided by for its appropriate use. In case of severe encrustations, management modalities are more complex. Many investigators have employed ESWL, laser-lithotripsy, PCNL, chemolysis using various chemolytic agents administered via a per cutaneous nephrostomy tube and open surgery either alone or in combination with other procedures.3,4 Especially in the presence of encrusted intrarenal segment of DJS, the use of PCNL and open procedures has been frequently reported..$^{5}$ In another study, Damiano R et al observed flank pain in $25.3 \%$, encrustations in $21.6 \%$, irritative bladder symptoms in $18.8 \%$, hematuria in $18.1 \%$, fever more than $104^{\circ} \mathrm{F}$ in $12.3 \%$ and stent migration in $9.5 \%$ of the patients. They also reported that morbidity and complications were minimal when the stent was left in situ for less than three months, but longer duration of stent retention was associated with increased frequency of encrustations, infections, calculus formation and obstruction of the stented tract. ${ }^{6}$ The available literature shows that DJ stent had been missed for a maximum of eight years and in most cases, the stent had fragmented spontaneously. ${ }^{7}$

In our institute no such type of case is reported in last ten years(2002-2012). In our case, the stent was in the urinary tract for 9 years after open surgery and it had migrated to the urinary bladder, where it acted as a nidus for the formation of large secondary vesical calculus which was removed by supra pubic cystolithotomy with successful achievement.

\section{REFERENCES:}

1. Saltzman B. Ureteral stents. Indications, variations, and complications. Urol Clin North Am 1988;15:481-91.

2. Singh I, Gupta MP, Hemal AK, et al. Severely encrusted polyurethane ureteral stents: management and analysis of potential risk factors. Urology2001; 58:526-531.

3. Tsai CC, Shen JT, Huang SP, et al: Use of a holmium laser to treat a forgotten double-J stent with whole stent encrustations: a case report. Med Sci 2009; 25 (10): 567-571.

4. Vanderbrink BA, Rastinehad AR, Ost MC, Smith AD: Encrusrated urinary stents: evaluation and endourologic management. J Endourol 2008; 22 (5): 905-912.

5. Acosta-Miranda AM, Milner J, Turk TM: The FECal Double-J: a simplifiedapproach in the management of encrusted and retained ureteral stents.J E ndourol 2009; 23 (3): 409415.

6. Damiano R, Oliva A, Esposito C, De Sio M, Autorino R, D'Armiento M. Early and late complications of double pigtail ureteral stent. Urol Int 2002;69(2):136-40.

7. Soyupek S, Oksay T, Koar A. Fragmentation of a forgotten double J stent and excreted with urine: Case report. Int Urol Nephrol 2003;35 (1):91-2. 


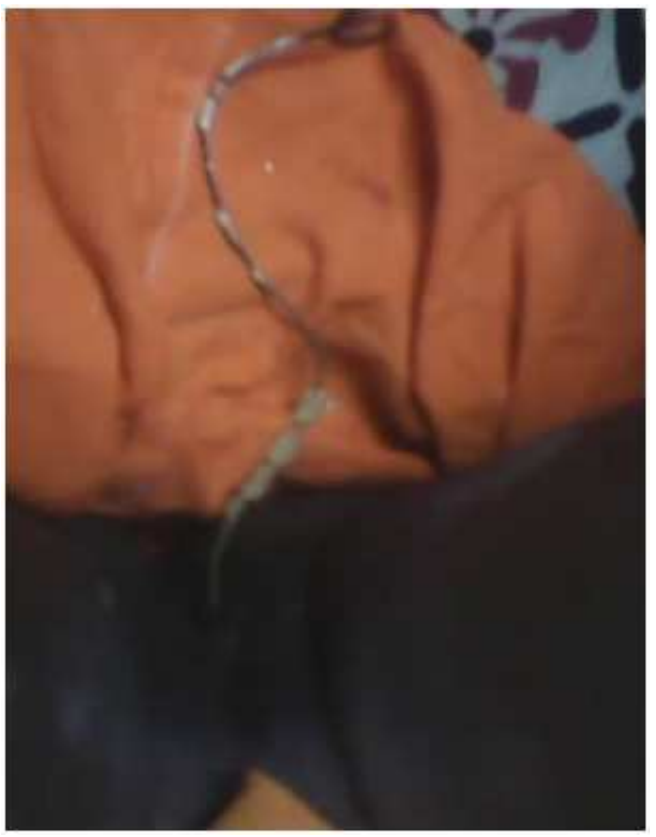

1(a)

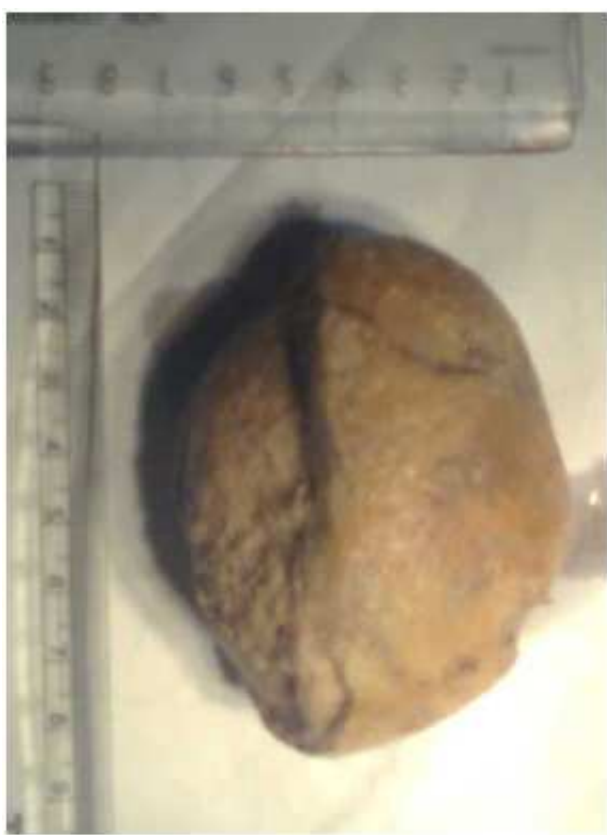

1(b)

Fig 1(a). Picture showing the encrusted D/J stent coming per urethra. 1(b). Picture showing a large vesical calculus measuring $8.5 \times 7 \mathrm{~cm}$.

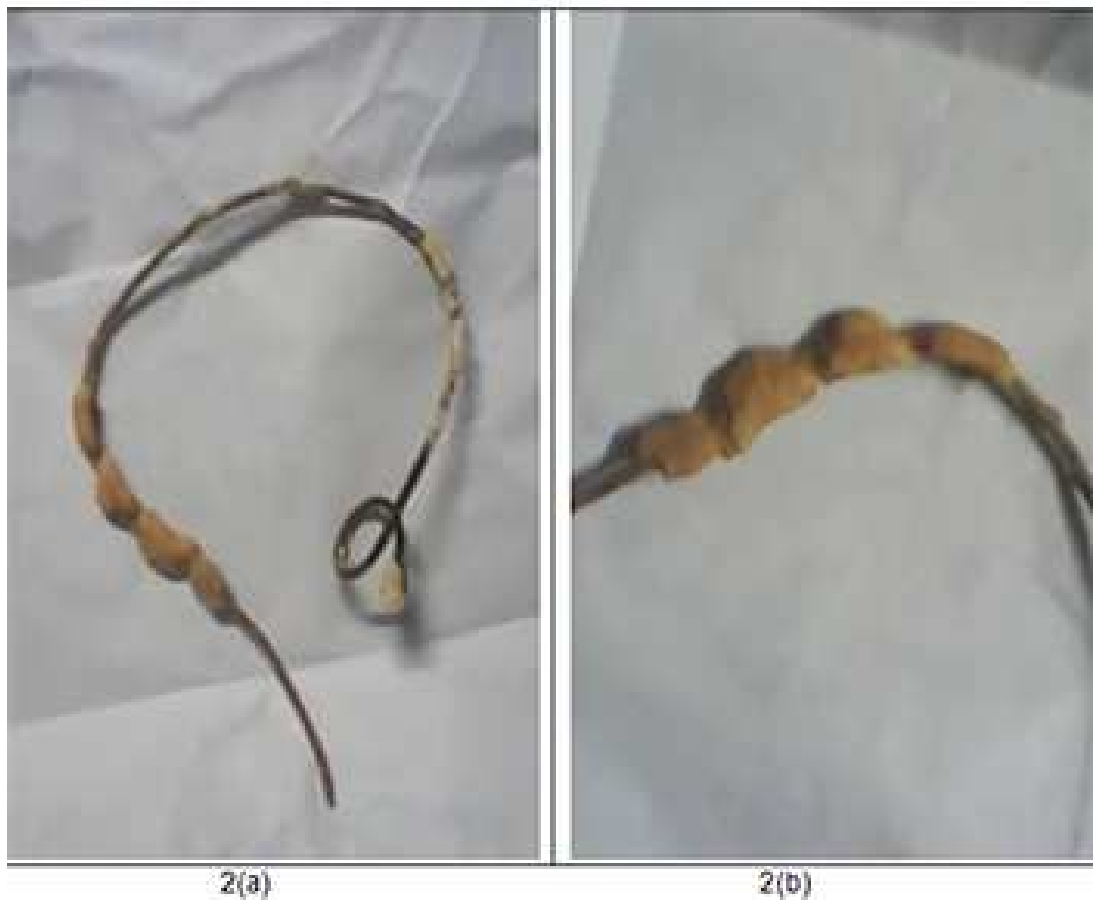

Fig 2(a), 2(b). Pictures of encrusted D/J stent after its removal 


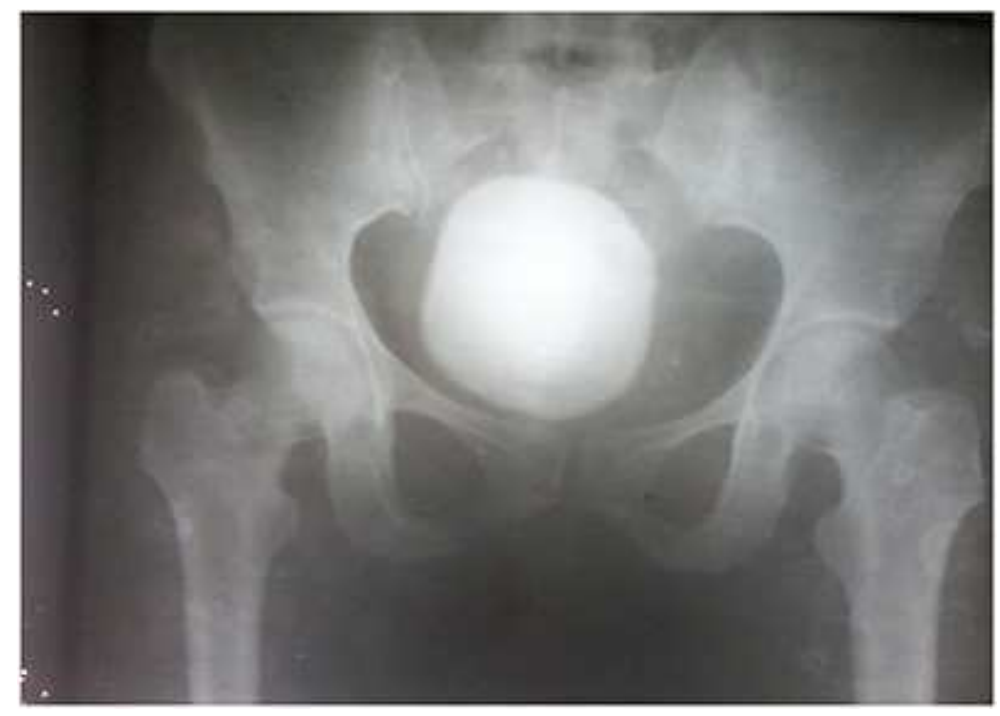

Fig 3. Picture X ray lower pelvis showing a large vesical calculus.

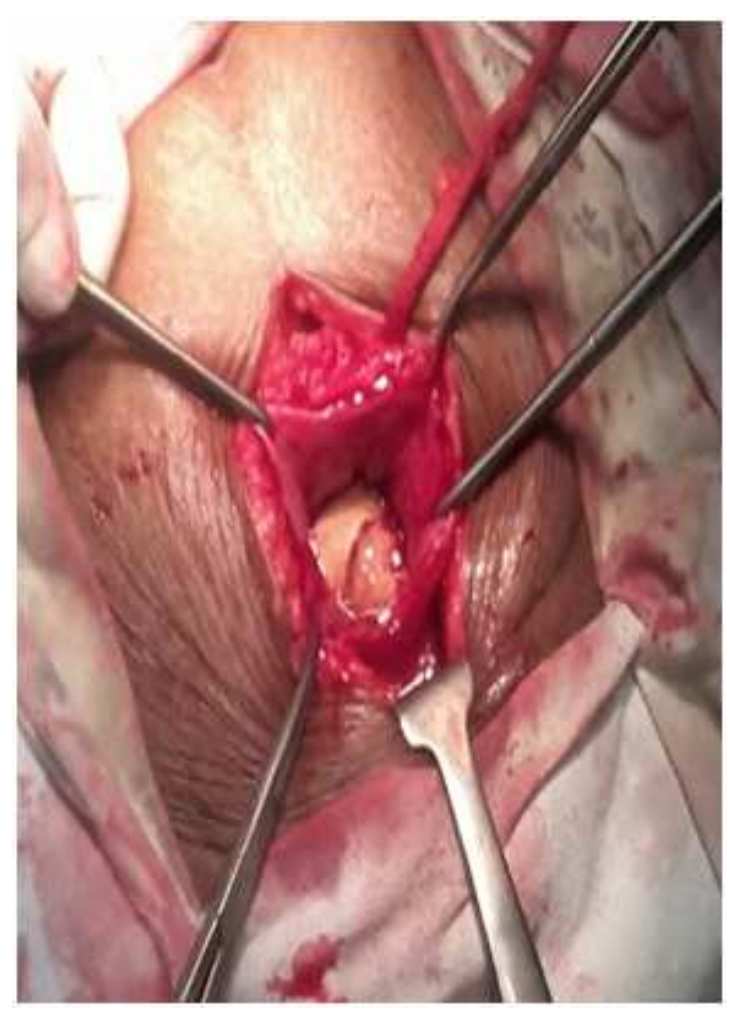

$4(a)$

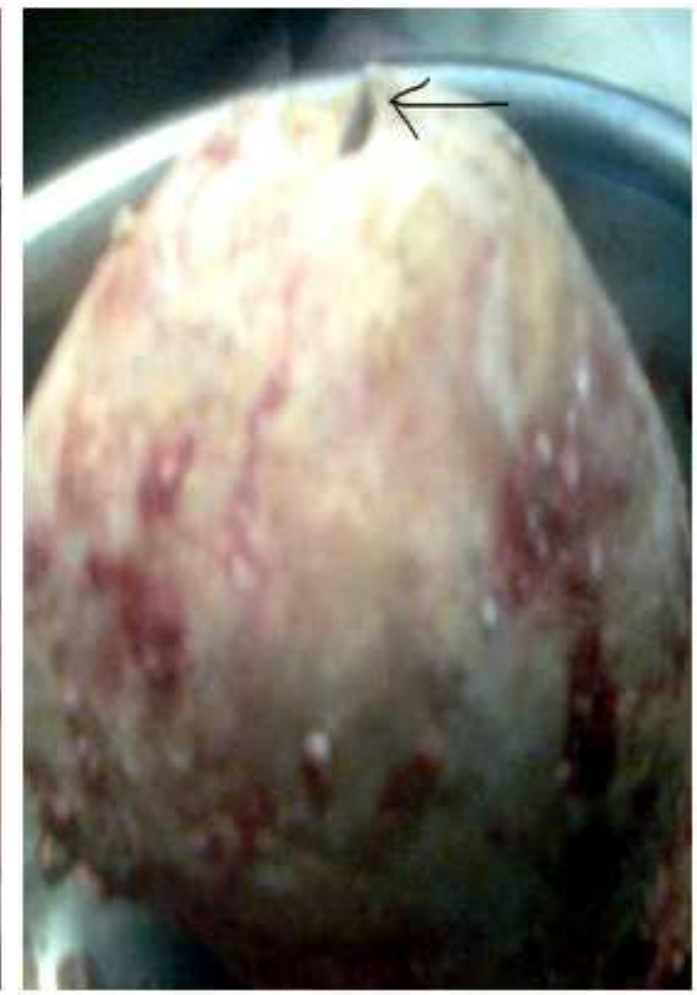

$4(\mathrm{~b})$

Fig 4(a). Intra operative picture showing a large vesical calculus.

Fig 4(b). Large vesical calculus showing an impacted stent. 